\title{
Emotional Athletes, Brainy Workers and other Hot New Developments: Multiple (re)problematizations of Heat Stress as an object of governance in northern Australia
}

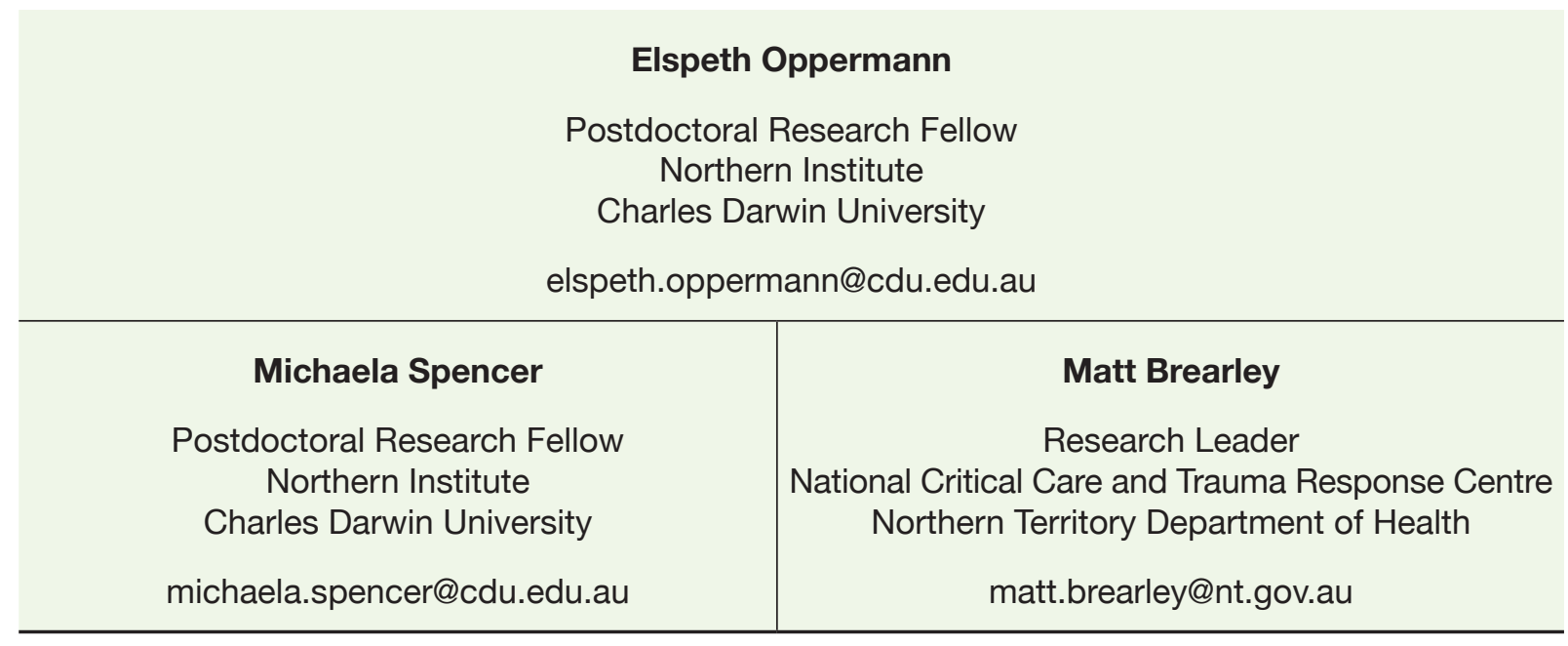

Keywords: Objects of governance, heat stress, problematisation, Foucault, northern Australia

This paper presents an effort to think about 'heat stress' as multiple objects of governance. In seeking to analyse this 'object' we draw on Foucault's account of 'problematization' (1985, 2009). Accordingly, heat stress is not understood as a mere description of an aspect of reality, but instead emerges as an object of knowledge from particular practices in particular times and places which draw together certain elements (Laclau \& Mouffe, 2001; Oppermann, 2013) such as concepts, measures and rules:

Problematization doesn't mean the representation of a pre-existent object, nor the creation through discourse of an object that doesn't exist. It denotes the set of discursive or non-discursive practices that makes something enter the play of the true and false and constitutes it as an object for thought. (Foucault, as cited in Flynn, 2005, pp.26-7).

Problematized in a particular way, the object becomes 'governable'. In analysing problematizations as producing a particular objects of governance, we consider four analytical questions: what is made visible, how is it known, how is it intervened in, and what subject(ivities) are produced (Dean, 2010)? That is, why are certain elements considered to be significant and problematic, how are these things understood and communicated, and what techniques and practices seek to manage these things to produce an idealised outcome, population or subjectivity? Because problematizations thus produce the social world as well as 'represent' it, problematizations are inherently political.

To trace the problematization heat stress as an object of knowledge and governance, we present extracts from a conversation between the authors, ${ }^{1}$ which explored the investigations and 
interventions of Dr Matt Brearley, an exercise scientist addressing heat stress. Re-telling some of Matt's experiences in trying to 'understand' heat stress brings into focus the contingency through which problematizations emerge. These stories also highlight how objects of governance are not necessarily singular, but can change over time and can be multiple (Mol, 2002). We notice in our conversation the ruptures of a singular heat stress that prompt its emergence as multiple objects, and the work that Matt finds himself doing to (re) problematize heat stress as a local object of knowledge and governance in different places and times.

Having journeyed through these multiple objects produced by different problematizations of 'heat stress', we then raise questions about how these objects of governance may come to relate as they participate in an emerging northern Australian governmentality centred on labour-intensive development.

\section{Athletic bodies: life beyond the footy field}

Matt begins the story of his engagement with 'heat stress' by telling of his arrival in Darwin, a city in the monsoon tropics of northern Australia. Arriving during the Dry season, the climate felt quite benign. So it was not something he took particular account of as an exercise scientist training young Australian Football League players. Part of their training regime was to 'load' the athletes' bodies, pushing them to the limits of what they could achieve in strength, speed and endurance, then allowing them to recover and adapt. This established training methodology works by periodically overloading and then unloading athlete's bodies to increase their fitness and capacity. And it worked, until suddenly, for no apparent reason, things started to go sideways:

We'd want to work on aerobic fitness... but sometimes [the players] would rock up and you would realise early in the session that there's nothing 'there.' You end up going nowhere because you can't get a stimulus into these guys.

The shift was hard to explain. It seemed that the athletes were suddenly lazy, not trying hard enough or deliberately disobeying the instructions they had been given. The overloading methodology appeared to be occurring in reverse: it was clear the athletes felt their bodies would not carry them as far as they had the day before and limits which had previously been surpassed were suddenly unreachable.

Matt's physiological monitoring of heat stress levels also provided bemusing results. Although the weather had become a bit hotter as the Dry season shifted to the Wet season, the athletes' core body temperatures did not seem to change significantly. They were not working hard enough on field to explain their apparent exhaustion. Why then, were they suddenly refusing to push themselves?

It was not the measurement of the athletes on the field that provided the key to unlocking the mystery:

I think it was through my own experiences that I started to think about it... I'd ride to work and ride home, about three hundred to four hundred kilometres a week, so it would be pretty hot and l'd be tired. l'd get home and have a [cold] shower and still be sweating, and I would have another shower and still be sweating. I found myself being really grumpy. The penny only really dropped when one day I just 'went off' at my children. I am quite strict, but I am also a clown and like to have fun. I remember going off and just seeing the look in their eyes, highlighting that my response was not justified. 
The look was one of surprise and shock. Matt was surprised and shocked himself, producing a "'crisis' moment" (Foucault, 1985 cited in Bacchi, 2012) that prompted him to broaden his account of heat stress to the emotional as well as the physical. The same incident had signaled that heat stress could be known in another way to that of core body temperature on the field: it could not only be experienced but could also be expressed in an emotive fashion. Now that emotion was 'visible' as an element of heat stress, new technologies of intervention in this new object became necessary to produce both a calm exercise scientist and well performing athletes:

We started taking a more global perspective... we were ramping up the work that our psychologist did with athletes, taking it into schooling. Talking to teachers about how [the kids] are going at school, talking to parents, and then you get a better feel for [what] these kids [had to deal with].

The young athletes were dealing with training as well as educational and social demands. In the Dry season they seemed better rested and had the energy to spend weekends enjoying themselves. They seemed able to deal with parents, boyfriends and girlfriends. Even with the loading of training, the cooler, dryer weather left them with enough energy in reserve to cope with daily life. When the Wet season started, social lives and relationships began to strain. It seemed that the young athletes' reserves of mental and emotional energy were tapped out, and something had to give. This had an impact on what training could be done, and whether loading in training might have negative effects on daily life, achieving a negative motivational impact rather than a positive one.

Matt's contingent personal experience of disruption and lived experience of heat stress produced a shift how he understood and sought to intervene in or manage heat stress. This in turn would produce heat stress as a different kind of object through his own practices as a coach and a researcher. Heat stress came to be governed as a much larger object: it now included the educational, social and emotional lives of athletes on and off the field as well as their physical exertion. In becoming alert to, and intervening in, the social lives of the athletes, sport psychologists and families alike expanded not only the way heat stress was understood, but the spaces and means through which it was managed. This meant the lived experience of 'heat stress' for the athletes also changed; this object of governance created a particular 'subject' not as the athlete-on-the-field but as an athlete-family-member-school-student, to be governed through training regimes that know the athlete's broader social demands, and bring them into the realm of calculation in the management of heat stress.

These 'new' technologies of heat stress management, attuned to this new 'problem,' produced a less-heat-stressed athlete by making sense of the 'old' elements of core body temperature through the new elements it made visible. This new heat stress object also produced a more 'effective' athlete, in part because the subject of the athlete itself was now extended to include emotional wellbeing and capacity as a result of the re-problematization of heat stress.

\section{Working heat stress in the workplace}

Our conversation moves to a different situation, where the practices that (re)produce heat stress as a particular object are very different. Matt tells us about working on heat stress in labour-intensive worksites where he learns to operate very differently. Finding staff unreceptive to abstract scientific explanations of heat stress, and with an intervention from a psychologist being an almost laughable proposition, Matt begins using different practices to constitute knowledge of heat stress. He tries to spend time 'on the floor,' observing practices, responses 
and talking to the employees. Many of the workers have been doing this job for the last thirty years, and they are not interested in someone new coming in and telling them that there's a problem, or that they ought to drink more water, take more breaks or use novel cooling methods to lower core body temperatures. Sometimes it's a matter of pride not to show any weakness in front of their mates, so they don't admit to feeling hot, tired, or nauseous.

Because heat stress is known differently in such locales, it needs to be managed differently as a result. The hierarchical social structures which had enabled interventions in sporting teams are not in play here: Matt's position as a coach and the enrolment of parents or psychologists in the technologies of intervention. So Matt finds himself using a classic liberal strategy of responsibilisation, appealing to extant subjectivities to enroll these in the task of self-government:

When I go into most worksites, there's got to be a few expletives in [my first few sentences] to shock the crews so they listen to the blunt messages being delivered. And then I talk about experiences with other groups, other work sites, other hardhat wearers, high-viz wearers etcetera. I think by speaking in those terms the work crews can relate to the message. Not all of it necessarily, but they can relate to [for example] being a grumpy bastard or making mistakes at work.

Matt's tactic here was to use language, examples and narratives that workers might associate with as a way to open up consideration of their own experiences of heat stress.

This approach to knowledge production does not mean scientific measurements are dropped entirely. One of the tools Matt takes with him into workplaces is a pill-sized gastrointestinal thermometer. This is swallowed, and measures and transmits the subject's core body temperature in real time. This provides hard numbers for just how hot individuals are as they work and how physiologically dangerous their core temperatures might be. Listening to this account, and acting on our own assumptions about the elevated place of quantified knowledge for an exercise scientist, Elspeth and Michaela asked Matt how people respond to hearing their 'numbers.' But he disrupts this epistemological stereotype, making clear that he is also aware of the interpretative 'power of numbers:'

So [the participants will ask me] 'How are my numbers.' I'll say, 'Numbers are numbers mate, they're good.' I'll try and give them less information because I need to observe them, I don't want them to alter their behaviour because I say, 'You're hot.' No, I want them to listen to their brain... So they're not looking at a number and then responding, but their brain will tell them everything they need to do, they just have to listen to it. I just need to know what signals the brain's getting and that's what these numbers tell me. I don't know perfectly, for instance you might be hot at 39 degrees, I might be hot at 38.5 degrees but it gives me a really good idea to say, 'This guy -- his brain is being inundated with the message 'I'm hot.'

Heat stress is still visible here as a physiological temperature, but it is being known here in two different ways: through the individual's interpretation of bodily sensations and through Matt's monitoring equipment.

With physiological limits for heat stress still part of workplace legislation and part of Matt's own problematization, it's important to know if people are pushing themselves beyond limits considered to be safe. For these independent adults, who might be monitored on the occasion Matt conducts his study, but who probably won't be monitored on any other day of their 
working lives, their 'brains' become the instrument of knowledge for governance. By making 'visible' physical sensations such as thirst, headaches and nausea as elements of heat stress, these act as triggers for interventions through taught practices of hydration, rest and cooling.

I want them to listen to their brain... I guess my work is to teach them a few strategies so they can do more work and not approach any disastrous limit, keeping them in the safe range so they're not robots in the heat.

However, such triggers enable interventions only when they are allowed to be voiced. In this particular site, it was the presence of workplace cultures as actively shaping the object of heat stress that produced a crisis of governance for Matt, and triggered a re-problematization of heat stress as also produced by cultural norms, requiring tactics and technologies of intervention sensitive to expletives and stories of 'others like you'. Perhaps most significantly, Matt became aware of his own role in co-producing heat stress as an object of governance through actively re-problematizing its appearance, means of knowing, or methods of intervention. The object of heat stress became re-definable through articulating an indirect route from expletives to an inherent part of labour-intensive work via the re-problematization of heat stress as an object of cultural and identity governance.

\section{The 'hot' topic of Northern Australian Development}

It is normal for Matt to travel to various worksites across the Northern Territory, and to speak with the employees as he looks for ways that heat stress might be better managed. However, he also notices that in a lot of workplaces people are profoundly hot and miserable, yet 'heat stress' does not exist as an object of knowledge or governance. In a region known for its tough conditions, there are surprisingly few policies guiding the management of heat stress in workplaces. The policies that do exist often borrow southern Australian practices and benchmarks, which are ill suited to the monsoon tropics of northern Australia. In many instances managers turn away Matt's offer of assistance whilst investigating major incidents because they cannot entertain the notion that there is a connection between wide-spread heat stress, fatigue, reduced emotional and decision-making capacity, and reduced safety and productivity - saying 'no, we've never had an issue with heat stress'.

The elements that Matt and other researchers have collected together as multiple objects of 'heat stress' might be the 'cause' of particular and tangible outcomes such as mistakes at work, 'going off' at kids, or reduced productivity or performance. In our conversation, we wonder: if heat stress presents such a compelling physical and emotional experience in our own bodies as researchers resident in the region, among fit young athletes, and through the daily experiences of workers, how is it still so invisible or absent as an object of governance in wider society? We explore whether there may be other objects or governmentalities already in place that prevent these elements of heat stress being made visible as an 'object,' with the result that heat stress is managed implicitly as a result of something else being governed overtly.

Matt observes that the high wages of workers on major projects in northern Australia distorts the willingness to intervene in or govern heat stress. Intentionally or unintentionally, high rates of pay, which overtly compensate for the 'remote' location and ensure schedules are completed on time, also have the effect of managing thermal discomfort:

If the pay is right then financial motivation overcomes people's fear of heat and aversion to discomfort and they get into it... When you win the tender, you do so knowing that for every week delay, you will pay an amount [a penalty] to offset 
that. Therefore to get it done quickly they'll pay crews extra, resulting in crews relocating temporarily or permanently to toil through two years of hell in the Northern Territory... [And the crews do it] to set up a better life for themselves. That's the game they're playing at the moment. The health outcomes... I have heard the reports of various medical and safety teams, but I don't precisely know the percentage of people presenting [for medical care]... but the reports are far more than I deem acceptable.

This governance of worker productivity indirectly governs heat stress, in the sense of managing its impact on productivity. However, because the physiological symptoms of heat stress are not rendered visible or explicit, let alone problematized in terms of effects on health and wellbeing, they are not being managed explicitly. This object of governance - workplace productivity conceived without heat stress - may be producing heat stress related health risks as well as longer-term declines in productivity.

The usual ethical question posed of governmentality - that it constitutes the subject - is inverted here, by asking: what are the ethical implications of not naming heat stress as an object of governance? The will to know and govern heat stress does indeed create new characteristics of the object, and open up and produce new facets of the 'subject' for technologies of governance. In Matt's stories, we saw this through the work of the exercise scientist, work that could easily be enrolled in a wider governmentality associated with productivity and development through labour-intensive industries.

Not knowing heat stress or the subject in this way might mean freedom from particular technologies of governance and a particular subjectivity. However, it also means that other governmentalities create their own objects of knowledge and governance, which may have less sensitivity to (as well as less control of) the physical and emotional experiences or our bodies as thirst, fatigue, nausea, and indeed, grumpiness. If heat stress is the name given to a materiality which, however differently it may occur, nevertheless names a physical and emotional sensation, what does it mean for the subject when heat stress is unnamed and unattended to? Matt provides the example of one worksite where the object of productivity did not include heat stress as a named or 'visible' element:

...they reckoned they had about $66 \%$ more rework at this worksite compared to all their other sites in the north. Rework is where crews have erred and the job needs to be deconstructed and started again. Because everyone was working long hours they were very tired, just flogging dead horses, and everyone's so tired but the boss thought, well we're behind, so we need to continue putting in the extra hours to complete the job.

For Matt, viewing the same elements of 'fatigue' and 'mistakes' through the object of heat stress created an alternative problematiizaton of productivity, which prompted a different response to that of 'flogging dead horses':

They were well behind schedule, you're not going to make up the lost time, so [instead] you've just got to realise [that] to limit our losses, we're going to give the guys more rest and improve productivity and safety.

Without heat stress existing as a clear object within the workplace, it is difficult for the 'boss' to account for it. Rather than allowing recovery time, the boss pushed the workers harder, making them more tired, and, it would seem, more likely to make mistakes. It seems that here 
there was no realisation as to why such unusually high levels of mistakes were being made and certainly no connection made to heat stress. It also seems that heat stress has exceeded - and undermined - the extant governmentality on its own terms, in this case, of profit and deadline driven productivity.

Whether or not heat stress is explicitly problematized within workplaces, the elements that are drawn together as 'symptoms' of heat stress, are often already involved in the everyday practices of these workplaces, although they may initially emerge as objects of governance as 'productivity' or 'worker health'. In this way, whether heat stress becomes an explicit object of governance or not, the emergent materiality that is able to be productively discerned or configured as heat stress may also be discerned as participating in the project of northern Australian development. The future configuration of heat stress, objects of governance and the overarching governmentality of northern development, remains an open and inherently political question.

Currently, heat stress in northern Australian workplaces has not been produced as a singular object of governance that configures subjects and practices to improve productivity or safety. However, as the number and scale of major projects in northern Australia increase, they will require large amounts of labour and work delivered continuously. Pushed to meet deadlines, some of the companies involved are beginning to have what Matt calls 'sentinel moments':

I think we need a moment, a period of time where [a major project] is delayed, causing a huge financial ramification. It's delayed because of work force shortage... because we cannot get people to do these jobs because people begin to say that it is just too hot to work to the required schedule...

Such a moment might bring together fragmentary elements of 'heat stress' into an identifiable object, visible at a larger scale. Rather than occurring for one subject here and there, governed incidentally or indirectly, heat stress would be re-problematized as an explicit object to be managed or regulated because of its implications for a governmentality of economic development that presumes subjects are healthy, efficient and productive.

\section{Multiple heat stresses as objects of governance}

We have noted in these stories how the specificities of the people and places in which heat stress emerges as an object means that it is a multiple object which often exceeds singular attempts to define it. We have presented some moments of crisis or rupture in which heat stress comes to be re-problematized. Through these transitions, the differing objects that emerge might share elements of materiality that are similar, but may include others that are entirely different. These are made (in)visible through the particular ways of knowing and technologies of intervention that in turn (re)produce certain subjectivities. At stake in these multiple imaginings and management strategies is not just the 'object' of heat stress itself, but the experience of the subject and indeed the nature of the subject and of the social. Yet particular problematizations and the objects they produce are also generative of, and limited by, the emergent array of other objects, knowledges and strategies, which produce wider rationales of governance or governmentalities.

While highlighting that elements may be included or excluded, and the production of subjectivities and social lives, we are not presenting an argument here for a particular problematization of heat stress as 'better' or 'worse'. Indeed, the self-fulfilling paradox of all attempts at governance is that any 'failures' encourage the re-imagining of the object and the continual extension of governance technologies. In Matt's experience as a practitioner, 
encountering 'failures' and re-problematizing heat stress as a result, we have shown just such an extension, which only reveals new planes of encounter, which further extend and embed the object (even as it changes, or indeed because it changes) in a web of relations of knowledge and attendant techniques and technologies of power or intervention. As such, the development of heat stress as a more comprehensive object of governance, and particularly one that interconnects with a dominant governmentality based on encouraging productive labour intensive industry, might enable an incredibly insidious productive power over life, or provide a surprisingly emancipatory platform for critiques of physical and social suffering.

Bringing these multiple objects and the practices that (re)produce them into view promotes the possibility of locally situated interventions into practices of governance and emerging governmentalities. Recognising this we hope that this account may have done justice to our own sense of disconcertment and the feeling of ethical tension we experience in wanting to offer an analysis of heat stress which may contribute to an emancipatory reduction of 'pain,' 'being grumpy' or needing medical attention in the workplace, without necessarily also becoming agents of the extension of biopolitical governmentality in the process.

Beyond the development of this expanded object of heat stress, it is perhaps the moments of rupture or crisis themselves that have the most emancipatory potential. In all of these stories, locally embodied experience of heat stress has exceeded any particular object of governance or wider governmentality. Yet by following the exercise scientist employed to make athletes or workers more productive, we have not been attendant to the potential for dissent, for exit or re-articulation by the other subjects on stage. It is their bodies, their non-compliant language and behaviour which have challenged Matt to develop particularly local interventions. In the subject's (re)production of self-monitoring such as Matt's call to 'listen to your brain', opportunities are made for experiential encounters in which a person's bodily experiences remain a personal and particular part of what heat stress is, and thus operate as a point of critique and departure from any given governmentality.

\section{References}

Bacchi, C. (2012). Why Study Problematizations? Making Politics Visible. Open Journal of Political Science, 2(1).

Dean, M. (2010). Governmentality: Power and Rule in Modern Society, (2nd ed.). London: Sage.

Flynn, Thomas, R. (2005). Satre, Foucault, and historical reason: a poststructuralist mapping of history, (Vol. 2). Chicago: University of Chicago Press.

Foucault, M. (2009). Security, Territory, Population: Lectures at the College de France 1977-1978. (Vol. 4). New York, NY: Macmillan Publishers.

Foucault, M. (1985). Discourse and Truth: the Problematization of Parrhesia. In J. Pearson (Ed.), Evanston, IL: Northewestern University.

Laclau, E., \& Mouffe, C. (2001). Hegemony and socialist strategy: towards a radical democratic politics, (2nd ed.). London: Verso.

Mol, A. (2002). The Body Multiple: Ontology in Medical Practice. Durham, NC: Duke University Press.

Oppermann, E. (2013). Why the discursive environment matters: the UK Climate Impacts Programme and adaptation to climate change in the UK. In L. Synga, K. O'Brien \& J. Wolf (Eds.), A Changing Environment for Human Security: New Agendas for Research, Policy and Action. London: Routledge. 